\title{
The oldest diving anseriform bird from the late Eocene of Kazakhstan and the evolution of aquatic adaptations in the intertarsal joint of waterfowl
}

\author{
Nikita Zelenkov \\ Acta Palaeontologica Polonica 65 (4), 2020: $733-742$ doi:https://doi.org/10.4202/app.00764.2020
}

A specialized diving lifestyle has repeatedly evolved in several lineages of modern and fossil waterfowl (Anseriformes), with the oldest previously known representative being the late Oligocene Australian oxyurine ducks Pinpanetta. However, diving specializations have never been previously documented for any of the primitive Paleogene anseriforms (

"stem-anatids"), and thus may be associated with the origin of modern anatid-like body plan. Here I describe a tarsometatarsus of a new duck-sized diving anseriform bird from the latest Eocene (late Priabonian) Kusto Svita in Eastern Kazakhstan, which predates the previously reported occurrence of diving specialization in Anseriformes by at least $6 \mathrm{MA}$. The new taxon Cousteauvia kustovia gen. et sp. nov. has an unusual and previously undocumented morphology, but partly resembles the stem-anatids Paranyrocidae and Romainvilliidae, thus representing the first known occurrence of diving adaptations in primitive non-anatid anseriforms. The evolutionary appearance of specialized waterfowl taxa in the late Eocene of Central Asia supports a view that this region might have played an important role in the evolution of morphologically derived Anseriformes. The structure of the intertarsal joint in basal and modern anseriforms is here further discussed in relation with adaptations for aquatic locomotion. The presence of elongate and evenly narrow condyles of the tibiotarsus in Anatidae and other swimming/diving birds allows a firm contact with the hyperprotracted tarsometatarsus at the initial phase of the propulsion. This morphology contrasts with the restricted condyles of Presbyornithidae, which indicate a different, strictly wading locomotory specialization. Cousteauvia obviously evolved diving specializations on the basis of a more primitive structure of the intertarsal joint.

Key words: Aves, Anseriformes, diving, evolution, intertarsal joint, Eocene, Kazakhstan, Central Asia.

Nikita Zelenkov [ㅁzelen@ paleo.ru], Borissiak Paleontological institute of Russian Academy of Sciences, Profsoyuznaya 123, Moscow, Russia. 
This is an open-access article distributed under the terms of the Creative Commons

Attribution License (for details please see creativecommons.org), which permits unrestricted use, distribution, and reproduction in any medium, provided the original author and source are credited.

FoF 